\title{
Pictorial pattern generalisation: Tension between local and global visualisation
}

\author{
Author: \\ Duncan Samson ${ }^{1}$ \\ Affiliation: \\ ${ }^{1}$ Education Department, \\ Rhodes University, \\ South Africa \\ Correspondence to: \\ Duncan Samson \\ Email: \\ d.samson@ru.ac.za \\ Postal address: \\ PO Box 94, Grahamstown \\ 6140 , South Africa \\ Dates: \\ Received: 16 Apr. 2012 \\ Accepted: 26 Aug. 2012 \\ Published: 26 Oct. 2012 \\ How to cite this article: \\ Samson, D. (2012). Pictorial \\ pattern generalisation: \\ Tension between local \\ and global visualisation. \\ Pythagoras, 33(3), Art. \\ \#172, 9 pages. http://dx.doi. \\ org/10.4102/pythagoras. \\ v33i3.172
}

This article engages with the notion of local and global visualisation within the context of figural pattern generalisation. The study centred on an analysis of pupils' lived experience whilst engaged in the generalisation of linear sequences presented in a pictorial context. The study was anchored within the interpretive paradigm of qualitative research and made use of the complementary theoretical perspectives of enactivism and knowledge objectification. A crucial aspect of the analytical framework used was the sensitivity it showed to the visual, phenomenological and semiotic aspects of figural pattern generalisation. A microanalysis of a vignette is presented to illustrate the subtle underlying tensions that can exist as pupils engage with pictorial pattern generalisation tasks. It is the central thesis of this article that the process of objectifying and articulating an appropriate algebraic expression for the general term of a pictorial sequence is complicated when tension exists between local and global visualisation.

\section{Introduction}

The use of number patterns, specifically pictorial or figural number patterns, has been advocated by numerous mathematics educators as a didactic approach to the introduction of algebra and as a means of promoting algebraic reasoning and supporting the fundamental mathematical processes of generalisation and justification (e.g. De Jager, 2004; Mason, Graham, Pimm \& Gowar, 1985; Pegg \& Redden, 1990; Walkowiak, 2010).

Number patterns presented as a sequence of pictorial terms have the potential to open up meaningful spaces for classroom exploration and discussion. However, despite the potential richness of such pictorial contexts, potentially meaningful pattern generalisation activities carried out in the classroom often become degraded to simple rote exercises in which the given pictorial sequence is simply reduced to an equivalent numeric sequence. As such, the generalisation process becomes a somewhat superficial or mechanistic exercise using set algorithmic methods. Whilst such an approach may well be successful in arriving at the correct general formula, the potential for genuine mathematical exploration offered by the context of the question is largely lost, with the generalisation process becoming 'an activity in its own right and not a means through which insights are gained into the original mathematical situation' (Hewitt, 1992, p. 7). As Thornton (2001) remarks, the danger with such an approach is that the focus becomes '... the development of an algebraic relationship, rather than the development of a sense of generality' (p. 252), the result being little more than disconnected algebraic formulation. This disconnection from the original context becomes particularly problematic when importance is placed on the justification or validation of the general rule, since algebraic expressions arrived at through this process become 'statements about the results rather than the mathematical situation from which they came' (Hewitt, 1992, p. 7). This is unfortunate since not only can generalisation of pictorial patterns lead to different but algebraically equivalent expressions of generality, thereby opening up excellent opportunities to engage with the notion of algebraic equivalence, but, as Orton (2004, p. 114) points out, justifying pattern generalisations provides pupils with legitimate and valuable experiences of proof en route to more formal mathematical proofs.

Number patterns presented in the form of a sequence of pictorial terms are thus far more than simply a visual representation of a given numeric pattern. In essence, the use of a pictorial context aims to exploit the visual decoding of the pictorial sequence to give meaning to the symbolic expressions constructed. Two critical aspects of this process are the ability not only to grasp in a meaningful way the perceived underlying structure of the pictorial context, but also the ability to use this structure to articulate a direct expression for the general term of the sequence.

\section{Theoretical background}

\section{Visualisation and figural apprehension}

As Duval (2006, p. 116) succinctly notes, there are many different ways of seeing. Consider the simple geometrical figure composed of a number of line segments (Figure 1). 


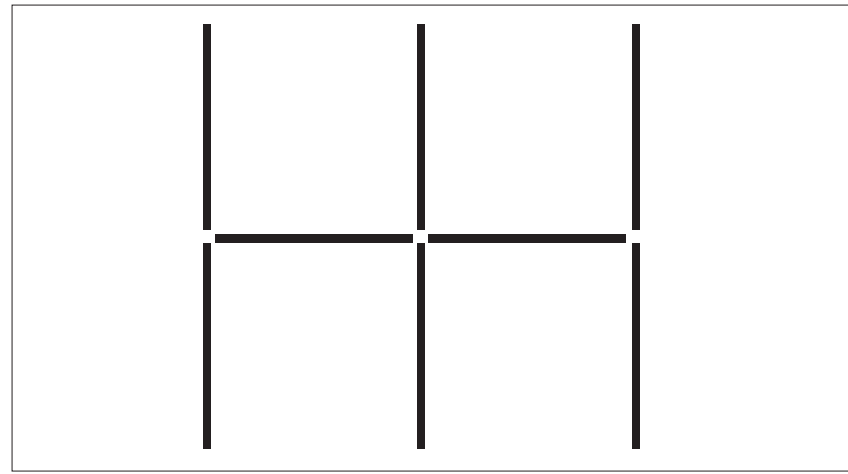

FIGURE 1: A simple geometrical figure.

Pupils visually interacting with the figure have the potential to perceive it in a number of different ways. In the same vein, a single pupil may be able to perceive the figure in multiple ways. If we take Figure 1 as an example, the figure could be perceived as comprising two overlapping Hs. Alternatively, it could be seen to comprise four overlapping squares, where the 'lids' of the top two squares and the 'bases' of the bottom two squares are missing. A third possibility is for the figure to be perceived as comprising three vertical lines with two shorter interconnecting horizontal lines. Yet another possibility is for the figure to be seen as a ' + ' symbol contained within two sets of vertical lines, one on either side.

If we now take the same image but place it in the context of a pictorial sequence, then the visual scenario is profoundly altered (Figure 2).

The middle diagram in Figure 2 is identical to the image shown in Figure 1. However, the contextual setting is no longer simply that of a geometrical figure. There is now a tacit suggestion that the image is part of a larger context, that it is part of a sequence of visually or structurally similar images. Given this new context, and the associated yet implicit sense of sequential growth, the middle diagram in Figure 2 could be perceived as a vertical line on the left followed by two sideways T-shapes. Alternatively, it could possibly be perceived in terms of a horizontal 'backbone' with vertical lines extending off it in two directions, upwards and downwards. The previous four visualisations are of course still possible, but the added context provides additional/ alternative perceptual features to be made apparent. Thus, by modifying the context, different ways of perceiving the figure are brought forth. On a note of clarity, use of the word 'feature' is not meant to imply that such features (or structures) are intrinsically contained within the image, simply waiting to be extracted or noticed by an observer. Rather, such features are seen to co-emerge from the interaction of a perceiver and the given figural context.

A further dimension is added to the visual image shown in Figure 2 when the pictorial sequence is used as a referential context for finding an algebraic expression for the number of lines in the $n$th diagram (or term) of the sequence. Although the context remains the same as that represented in Figure 2, the process of generalisation provides a further layer of complexity as it necessitates not only the perception of the figure within the context of a sequence of similar figures, but it requires the perception of generality, the notion that the figures in the sequence have a related structure. Finally, there is a requirement that this perceived generality must be articulated in such a way that it can be written in the form of an algebraic expression. A critical aspect of the visualisation process thus relates to the usefulness or meaningfulness of the perceived structure of the image in terms of the extent to which this perceived structure supports or hinders the process of generalisation.

Drawing on the nomenclature used by Fischbein (1993), figures such as the image shown in Figure 1 could be said to contain figural properties. What one sees in the image is a result of the Gestalt laws of figural organisation (Helson, 1933; Katz, 1951; Wertheimer, 1938; Zusne, 1970, pp. 111-135). Images such as that shown in Figure 2 could be said to contain both figural properties and conceptual qualities. What one sees in the image is still based on the Gestalt laws of figural organisation, but this is further influenced by the additional conceptual qualities of the image that have been added by virtue of the image being contextualised, in this case within a sequence of similar images. The critical point here is that an underlying tension is likely to pervade visual strategies applied to pictorial pattern generalisation tasks as a result of the relationship between the figural properties and conceptual qualities of the given images.

\section{Local versus global visualisation}

Visual approaches to pictorial pattern generalisation can be divided into two broad categories. The first category, which I previously termed local visualisation (Samson, 2011a), incorporates those visual strategies that are characterised by the foregrounding of the local additive unit - that is the structural unit which is added to (or inserted into) a given pictorial term in order to form the next term in the sequence.

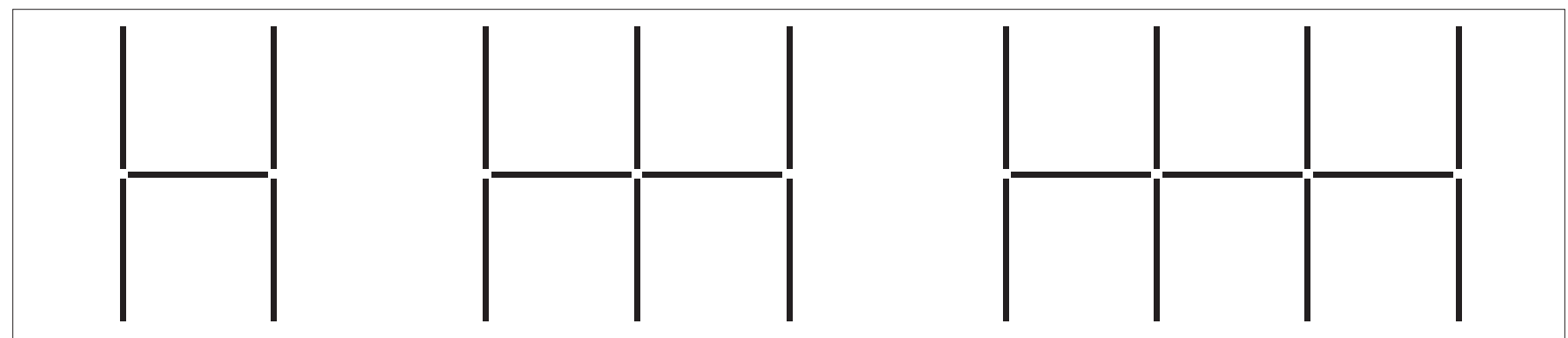

FIGURE 2: A simple pictorial sequence. 


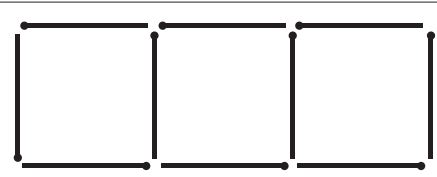

Shape 3

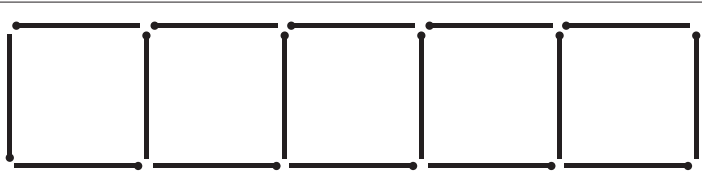

Shape 5

FIGURE 3: Term 3 and Term 5 of a typical pictorial sequence.

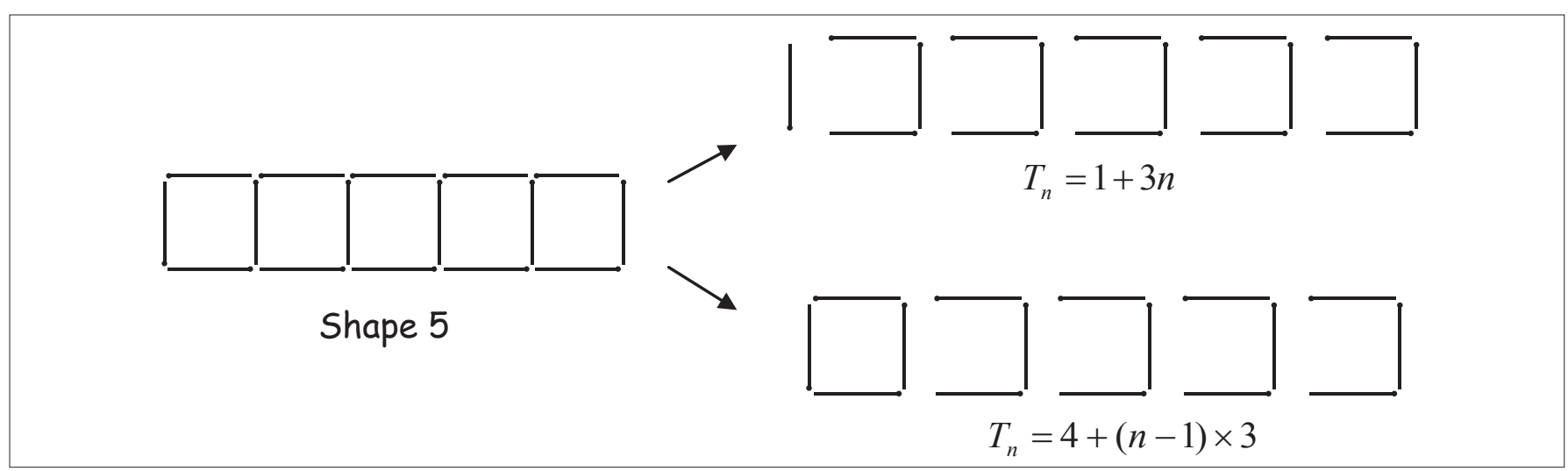

FIGURE 4: Local visualisation of Term 5.

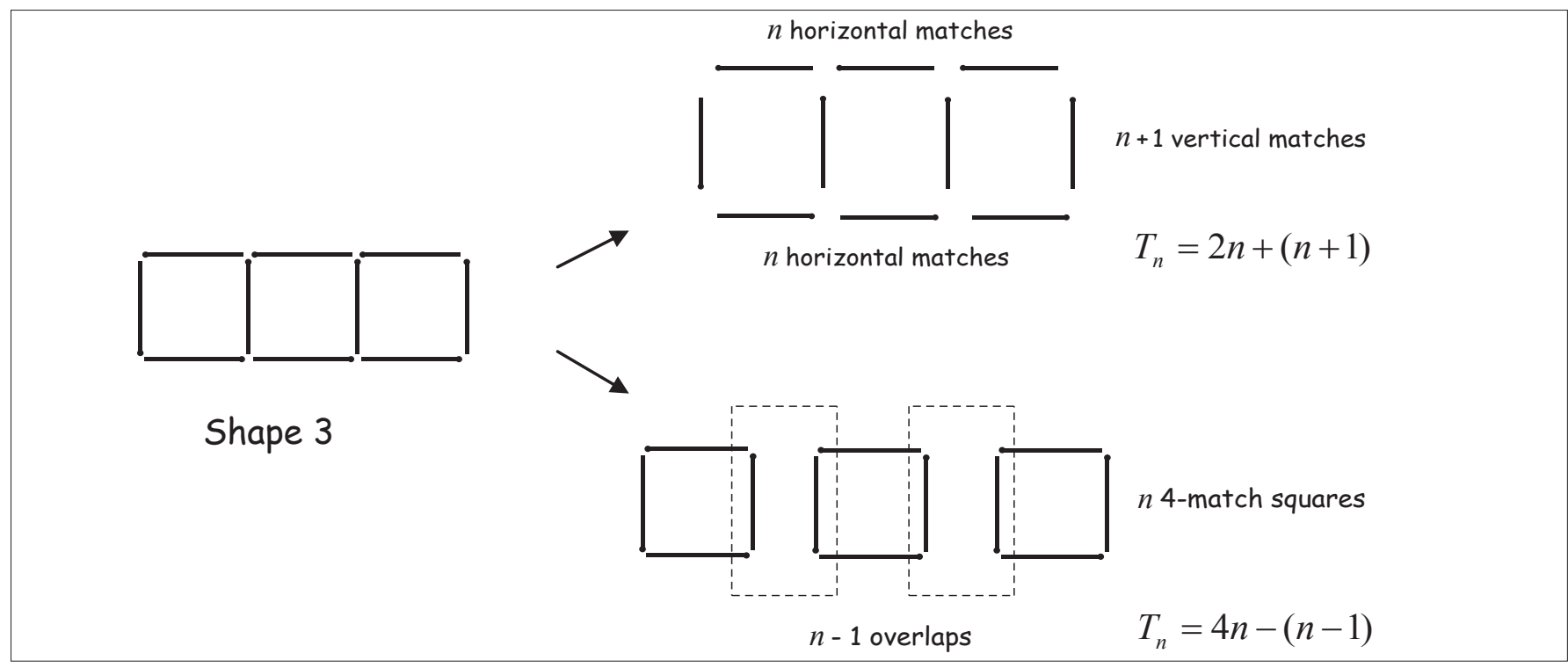

FIGURE 5: Global visualisation of Term 3.

This focus on the structural additive unit represents an iterative or recursive process of visual reasoning. The second category, which I previously termed global visualisation (Samson, 2011a), incorporates those visual strategies characterised by a more holistic or global view, where each term of the pictorial context is seen in terms of a generalised structure that does not make use of the iterative addition of the additive unit.

By way of example, consider Figure 3, which shows Term 3 and Term 5 of a pictorial sequence ${ }^{1}$.

Using a local visualisation, one could reason that to get from one term to the next requires the addition of three matches

1.On a note of clarity, the expressions 'shape' and 'term' are used synonymously and interchangeably throughout the text. Both expressions refer to the independent variable (i.e. the position of the term) in a sequence. in the form of a backwards C-shape, the visual additive unit. The visual deconstruction of the pictorial context based on this local visualisation could be based on either (1) an initial starting match and $n$ multiples of three matches in the form of a backwards $\mathrm{C}$-shape (the additive unit), yielding the general formula $T_{n}=1+3 n$, or (2) a 4-match constant followed by $(n-1)$ multiples of the visual additive unit, yielding the general formula $T=4+(n-1) \times 3$. Both of these scenarios are illustrated in Figure 4.

By contrast, global visualisation is characterised by a more holistic view that does not make use of the iterative addition of the additive unit. Rather, each pictorial shape is visualised in terms of a generalised structure.

By way of example (see Figure 5), one could subdivide each term of the given pictorial context into an upper row of $n$ 
horizontal matches, a lower row of $n$ horizontal matches, and a central row of $n+1$ vertical matches, thus yielding the general formula $T_{n}=2 n+(n+1)$. Alternatively, each term could be seen to contain $n$ overlapping squares, each made up of four matches, thus giving a count of $4 n$ matches. However, this would result an overcount because there are $n-1$ overlaps. Correcting for this overcount gives the final formula $T_{n}=4 n-(n-1)$. These two different global visualisations are illustrated in Figure 5.

Duval (1998, p. 41) makes the pertinent point that most diagrams contain a great variety of constituent gestalts and subconfigurations. Critically, this surplus constitutes the heuristic power of a geometrical figure, since specific subconfigurations may well trigger different visual generalisations. Thus, within the context of figural pattern generalisation, the processes of visualisation and generalisation are deeply interwoven, and a complex relationship is likely to exist between different modes of visualisation. One of these underlying tensions is that between local and global visualisation, and it is this particular tension that forms the focus of this article.

\section{Enactivism and knowledge objectification}

The broader study (Samson, 2011b) of which this article forms a part centres on two key theoretical ideas, enactivism (Maturana \& Varela, 1998; Varela, Thompson \& Rosch, 1991) and knowledge objectification (Radford, 2003, 2008). The manner in which these complementary theoretical lenses combine to provide a rich tool for analysis is described elsewhere (Samson \& Schäfer, 2011), but a brief overview is presented here.

The basic tenet of enactivism is that there is no division between mind and body, and thus no separation between cognition and any other kind of activity. Within an enactivist framework, there is a purposeful blurring of the line between thought and behaviour (Davis, 1997, p. 370), and cognition is thus viewed as an embodied and co-emergent interactive process. From this theoretical stance, as Davis (1995, p. 4) points out, language and action are not merely outward manifestations of internal workings, but should rather be seen as 'visible aspects of ... embodied (enacted) understandings'. Radford's (2008) theoretical construct of knowledge objectification resonates strongly with an enactivist theoretical framework since it foregrounds the phenomenological and semiotic aspects of figural pattern generalisation. Knowledge objectification thus represents an ideal theoretical construct to critically engage with pupils' whole-body experience and expression whilst they explore the potentialities afforded by a given pictorial pattern generalisation task.

Knowledge objectification is a theoretical construct to account for the manner in which learners engage or interact with a given scenario or context in order to make sense of it en route to a stable form of awareness (Radford, 2006, p. 7). Knowledge objectification is premised on two notions. Firstly, semiotic means such as gestures, rhythm and speech are not simply epiphenomena, but are seen as playing a fundamental role in the formation of knowledge (Radford, $2005 a$, p. 142). Secondly, in order to study the process of knowledge production one needs to pay close scrutiny to multiple means of objectification, for example words, linguistic devices, gestures, rhythm, graphics and the use of artefacts, where '...meaning is forged out of the interplay of various semiotic systems' (Radford, 2005b, p. 144). It is through this multi-systemic, semiotic-mediated activity that the objects of perception, or rather the objects of knowledge, progressively emerge - a process of 'concept-noticing and sense-making' (Radford, 2006, p. 15). Importantly, from an enactivist stance, use of the word 'object' by no means suggests that these 'objects' are pre-existing properties inherent in the environment. Rather, the 'objects' of perception are brought forth through the co-determination of knower and known, the co-evolution of individual pupils and their surroundings.

\section{Methodology}

The broader study (Samson, 2011b) of which this article forms part is oriented within the conceptual framework of qualitative research, and is anchored within an interpretive paradigm. The study aims ultimately to gain insights into the embodied processes of pupils' visualisation activity when engaged in figural pattern generalisation tasks through an in-depth analysis of each pupil's lived experience. A mixedgender, high-ability Grade 9 class of 23 pupils constituted the research participants for the broader study (Samson, 2011b). From this group of 23 pupils, seven research participants were identified as preferring a visual mode when solving pattern generalisation tasks. These seven research participants were individually provided with a linear pattern presented in a pictorial context and were required to provide, in the space of one hour, multiple expressions for the $n$th term of the sequence. Tools such as paper, pencils and highlighters as well as appropriate manipulatives such as matchsticks were provided. Participants were asked to think aloud whilst engaged with their particular pattern generalisation task, and the researcher also prompted the participants to keep talking or provide further explication as and when necessary. Each session was audio-visually recorded and field notes were taken. Audio-visual recordings were analysed with specific reference to how participants made use of multiple means of objectification en route to a stable form of awareness. These means of objectification included the use of words, linguistic devices, metaphor, gestures, rhythm, graphics and physical artefacts. These processes of 'coming to know' were carefully scrutinised through multiple viewings of the audio-visual recordings of each research participant.

The data analysis was guided by an enactivist methodological framework in which the researcher and research environment are seen to co-emerge (Reid, 2002). This interdependence of researcher and context was characterised by a flexible and dynamic process of investigation (Trigueros \& Lozano, 2007). The iterative and reflexive process of co-emergence was built up over time through the use of multiple perspectives and the continuous refinement of methods and data analysis protocols. Audio-visual data was examined repeatedly in different forms (e.g. video and transcript) and in conjunction with additional data retrieved from field-notes and participants' worksheets. In 
addition, nodes of activity that seemed particularly interesting were identified and meticulously characterised with reference to the various semiotic means of objectification in the form of descriptive vignettes.

\section{Ethical considerations}

Before the broader study started, formal permission to conduct the research was obtained from the principal of the school in question. Anonymity of both the school and the research participants was assured, and appropriate pseudonyms are used throughout the text when referring to research participants. In addition, only those pupils who agreed to participate in the study through voluntary informed consent formed part of the research sample, and participants had the freedom to withdraw from the study at any stage without explanation. In the case of participants who were audio-visually recorded, written consent was obtained from each research participant as well as from each participant's parents or legal guardians.

From a more philosophical standpoint, there is also an important ethical consideration stemming from the enactivist theoretical underpinnings of this study. In enactivist terms we need to be sensitive to the notion that '... our actions have the potential to alter the worlds and possibilities of others' (Simmt, 2000, p. 158). Furthermore, an enactivist stance compels us to see each person's certainty as being '... as legitimate and valid as our own' (Maturana \& Varela, 1998, p. 245). Sensitivity to both of these ethical considerations was maintained throughout the study.

\section{Reliability and validity}

In terms of reliability and validity considerations, not only the appropriate choice of the figural pattern generalisation questions themselves, guided by pertinent literature, but also the nature of their presentation were of critical importance. A literature review and previous research experience (Samson, 2007) suggested that linear sequences of the form $a x \pm c(c \neq 0)$ would be most appropriate in terms of eliciting rich data.

It has been shown that patterning tasks presented with consecutive terms encourage a recursive strategy (Hershkowitz et al., 2002; Samson, 2007) and thus tend to draw attention away from global structural features that could potentially co-emerge through the interaction of a perceiver and the given figural context. Since not all patterning tasks could be presented unambiguously using a single term, it was decided to use two non-consecutive terms for all questions. This purposeful decision was thus not intended to encourage global visualisation per se, but rather to ensure that the potential for global engagement with the pictorial context was not discouraged by virtue of terms being presented consecutively.

In addition, data collection and analysis protocols were sensitive to the enactivist underpinnings of the study, and thus made use of multiple data sources and approaches to data handling (as previously outlined). This process acted as a form of triangulation, which sought to ensure validity.

\section{Findings and discussion}

Participants were presented with two non-consecutive terms of a linear pictorial sequence rather than a series of consecutive terms. Nonetheless, during their engagement with the presented pictorial terms, all pupils created physical instantiations of specific terms of their pictorial sequence through the process of drawing. This drawing process was in many ways a two-edged sword. In some instances, the physical process of drawing led to the emergence of structural commonalities or regularities. This supported the generalisation process where these regularities were algebraically useful (i.e. where the generality of what was noticed in the phenomenological realm could be readily expressed using algebraic symbolism). However, the physical process of drawing often led to attention being focused on the recursive nature of the step-by-step process of construction, thereby foregrounding local considerations rather than allowing for a more holistic or global apprehension. This often resulted in an underlying tension between these two different modes of visualisation.

\section{An illustrative vignette}

The following vignette attempts to capture and characterise the tension between local and global visualisations as evidenced by the generalisation activity of one of the research participants (Terry, a high-ability Grade 9 pupil).

\section{Part 1}

Terry was presented with two non-consecutive terms of a typical pictorial sequence (see Figure 6).

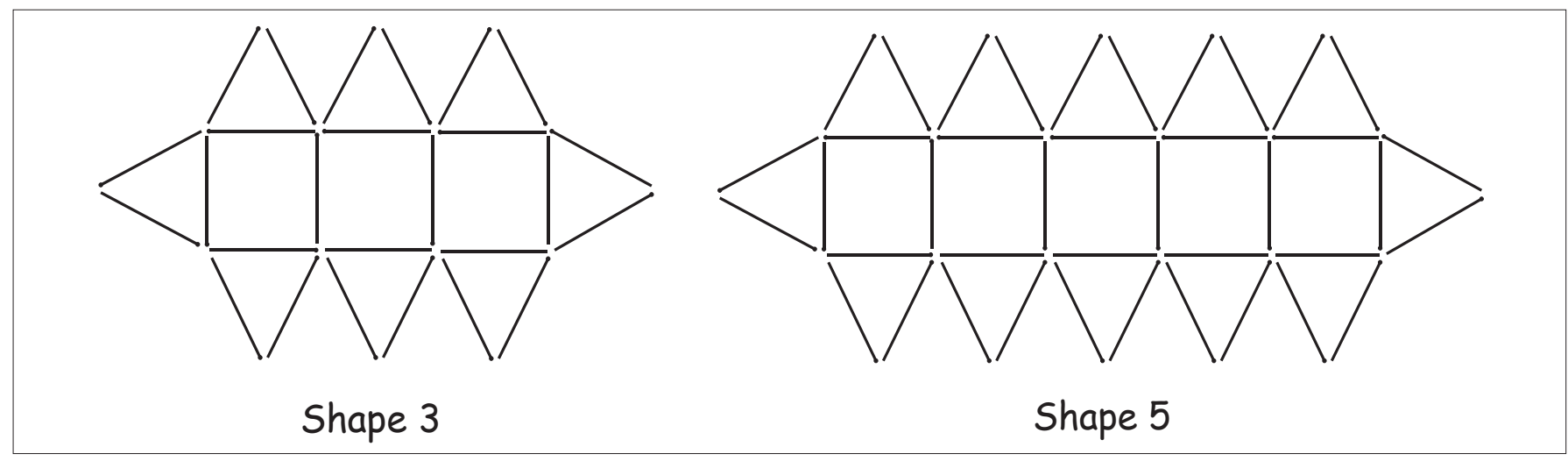

FIGURE 6: Pictorial pattern presented to Terry. 
After staring at the two terms for a few seconds, he remarked:

It seems like it's basically just adding on the same sort of thing again, every time, and then just finishing it off with that [indicating the rightmost > shape]. (Samson, 2011b, p. 131)

After making this remark he carefully drew Term 4 in a very structured manner. He began by drawing the three matches of the leftmost triangle. Thereafter he drew the middle section of the structure in a very rhythmic fashion: 4,5,6 . 7,8,9 .. $10,11,12 \ldots 13,14,15$. Interestingly, instead of drawing each group of three matches in the flowing form of a backward C-shape (top match, then vertical match, then bottom match) which would have been slightly more economical, he instead methodically drew each group of three matches by first drawing the top horizontal match, then the bottom horizontal match, and then finally the vertical match. To check that he had drawn the correct number of matches for Term 4 , he then carefully counted the four 'squares' in the diagram before adding on the two oblique matches on the far right. After completing the middle section of the diagram, he drew a series of inverted V-shapes across the top of the structure (rhythmically drawing them in pairs from left to right) and finished the diagram by drawing a series of V-shapes along the bottom of the diagram, once again in rhythmic pairs from left to right (Figure 7).

Based on this drawing procedure, Terry was able to arrive at the formula $7 n+5$ :

So you started off with your little triangle [indicating the leftmost $<$ shape] so that's obviously +2 , then you finish it off with a little triangle again [indicating the rightmost > shape], plus another 2, so it's +4 ; and then however many things in between, just work out how many it is for that [indicating the 7-match additive unit] (...) well how many it is for the top triangle, bottom triangle and then plus that one [indicating the vertical match connecting the top and bottom triangles in the 7-match additive unit]. (Samson, 2011b, p. 132)

At this point Terry wrote down the formula $7 n+4$. However he quickly realised that he had not taken into account the first vertical match from the left:

Shape 3 is Term 3, it's got 3 of these little squares like that [pointing to the three central squares of Term 3] and Shape 5 has 5. So then you've got these 2 [indicating the leftmost < shape] so you start off, there's +2 , there's another 2 [indicating the rightmost $>$ shape] plus 4 , then you've already got [points to the leftmost vertical match and realises he has missed it out] - oi! (...) With the front triangle [indicating the triangle formed from the leftmost < shape and the leftmost vertical match] it's the full triangle that you're starting off with, so it's 1, 2, 3 matchsticks. With the end one you've already got the (...) base of the triangle coming from the previous square. (Samson, 2011b, pp. 132-133)

Terry thus gave his final formula as $7 n+5$ which he subsequently altered to $3+n(3+3+1)+2$ as being more representative of how he was visualising the pictorial context (Figure 8).

Both expressions represent a local visualisation since they are based on a recursive addition/insertion of the 7-match additive unit. In the altered version of the formula, the 7-match unit is further subdivided into a 'top triangle', a 'bottom triangle' and a vertical line. An important distinction here is that Terry is not seeing each term as being holistically

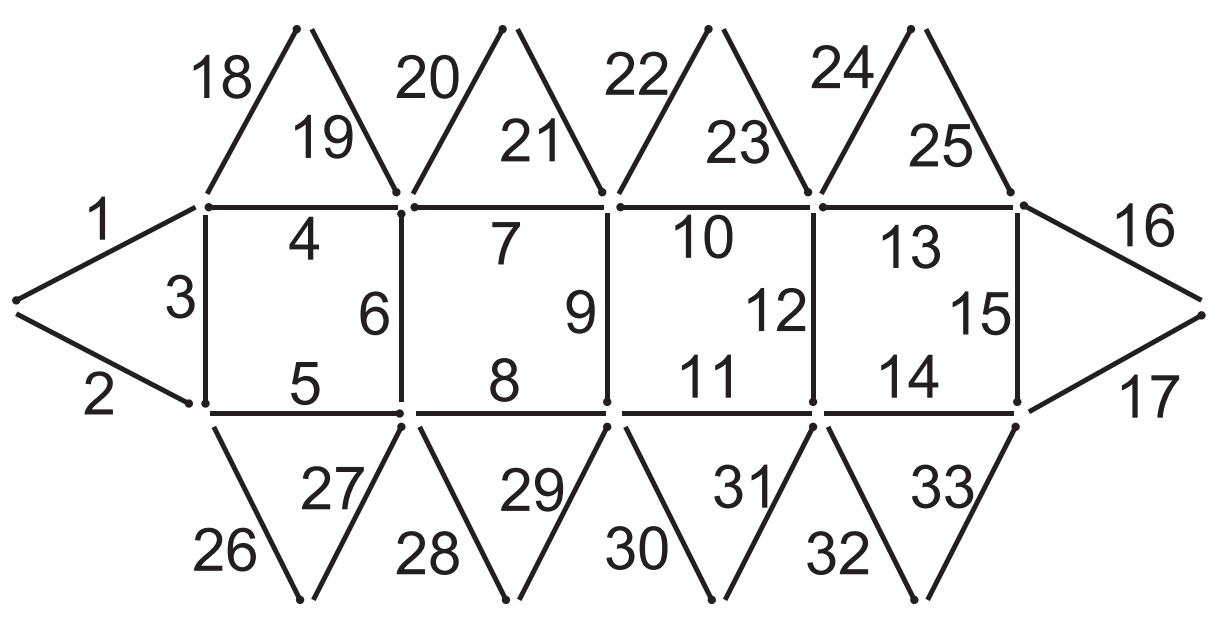

FIGURE 7: Terry's drawing procedure for Term 4.

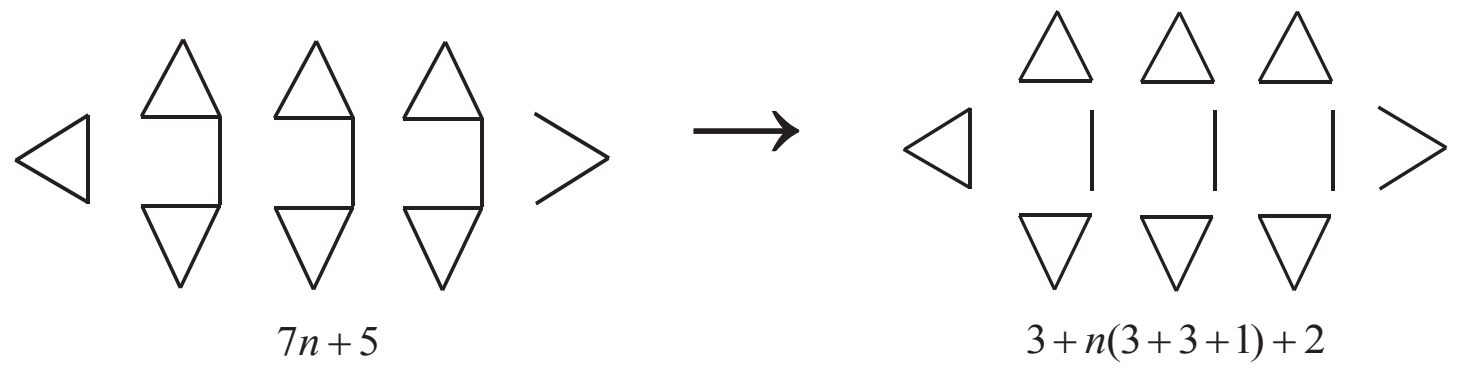

FIGURE 8: Two different formats of Terry's initial visualisation. 
composed of multiple 7-match units enclosed between a triangle on the left and a > shape on the right. Rather, the 7 -match unit is seen as an additive structural unit in that it is recursively or iteratively added to (or inserted into) an existing term in order to construct the next term in the sequence, as evidenced by Terry's remark 'it's basically just adding on the same sort of thing again, every time.'

An interesting aspect of Terry's discussion is his frequent reference to squares in the pictorial terms. He makes express reference to the fact that the $n$th term in the sequence would contain $n$ 'little squares'. In addition, when he initially drew Term 4 he did so by drawing the central structure first and then checking that he had drawn the correct number of matches by quickly counting the four squares. However, these squares do not feature anywhere in either of the two versions of his initial formula. In fact, the horizontal matches from these squares are seen to form part of an upper and lower triangle. Thus, after visually deconstructing the diagram into triangles, the squares become negative space as the matches that originally formed them have been apportioned to different component parts. Nonetheless, Terry continued to refer to them as a helpful structural unit. There are two possible reasons for this that are worth considering. Firstly, the ultimate aim of the patterning task from Terry's perspective is to arrive at an algebraic expression for the general term through a process of visualisation. It is possible that this goal had an unconscious influence on the visualisation process since some visualisations would be algebraically more useful than others - for example, squares would overlap and a correction would thus be necessary for the resulting overcount. A second possibility is that there is a tension between local and global aspects of the pictorial context. Local considerations focus on the additive unit by virtue of attention being focused on the step-by-step process of constructing the next term from the previous one. It is possible that this local focus obscured a more global outlook where the structural unit of a square could be properly incorporated into the general expression.

\section{Part 2}

After silently and motionlessly staring at the two printed pictorial terms for a few minutes he made the following comment:

What I'm trying to do now is almost use the squares. So now instead of having that sort of backwards $\mathrm{C}$, actually have a fullon square (...) that gets connected to another square [gesturing to the right with his pencil], that then, just got to take out that one [indicating the overlapping match between two squares], and gets connected to another square [making multiple gestures further to the right with his pencil]. (Samson, 2011b, p. 134)

Whilst Terry was explaining his strategy, he made use of a number of crucial semiotic means of objectification. The first of these was his gesturing to the right whilst saying the words 'that gets connected to another square'. This indexical or deictic gesturing was specifically related to Term 3, which Terry had in front of him. He thus used the gestures to signify existing physical structures in the particular diagram he was looking at. His second set of gestures, accompanying the words 'and gets connected to another square' mark a transition from existential signification to what Sabena, Radford and Bardini (2005, p. 134) refer to as imaginative signification. This second set of gestures moves from indicating materially instantiated aspects of the pictorial term to miming an ongoing sequence of connected squares, squares that are not yet materially present. We thus see a progressive distancing from the physical referent. Another important aspect of Terry's objectification process is his use of the words 'another square'. These words serve an important generative action function in terms of objectifying the generality of the interconnecting squares through an imaginative conception of iterative potential action. This linguistic device supports the process of objectification by allowing the recursive addition of squares to be '... repeatedly undertaken in thought' (Radford, 2000, p. 248). However, and critically important in terms of the local-global visual tension, the words 'and gets connected to another square' foreground an iterative process. Thus, whilst supporting an important generative action function in terms of objectifying the generality of the structural unit of the square, they also tend to focus attention on the recursive nature of step-bystep construction, thus drawing attention away from a more holistic view of the overall general structure.

Terry then went on to draw Term 4. Interestingly, the order in which he drew the various lines did not seem to correlate with his description of overlapping squares. Instead, his drawing process seemed to suggest a subdivision into a triangle at either end, two rows of horizontal matches, a row of vertical matches, and V-shapes at the top and bottom.

After completing his drawing of Term 4, Terry sat staring at it for just over a minute before commenting: 'I had something and now I've, I had something else but now I've lost it.' It thus seems that his initial idea of using overlapping squares came from a flash of insight that has since receded. It is possible that this may have been at least partially precipitated by Terry's drawing of Term 4 in a manner which did not mimic his initial visualisation of overlapping squares. In this instance, it is possible that the drawing process itself obfuscated the visual apprehension. However, another interpretation of the data could suggest that the drawing process actually reflects a competing, albeit unconscious, visualisation of the pictorial terms, thus suggesting an underlying visual tension between two different apprehensions of the pictorial context.

Terry then came up with the formula $3+n(4-1)+4 n+2$. The ' 3 ' at the beginning of the formula represents the starting triangle on the far left whilst the ' +2 ' at the end of the formula represents the $>$ shape at the extreme right of each term. Terry described the $n(4-1)$ portion of his formula as representing 'each square minus the one that's being taken up by either the previous one or the next one' whilst the $4 n$ is required for 'the triangles above and below it'. Although he 


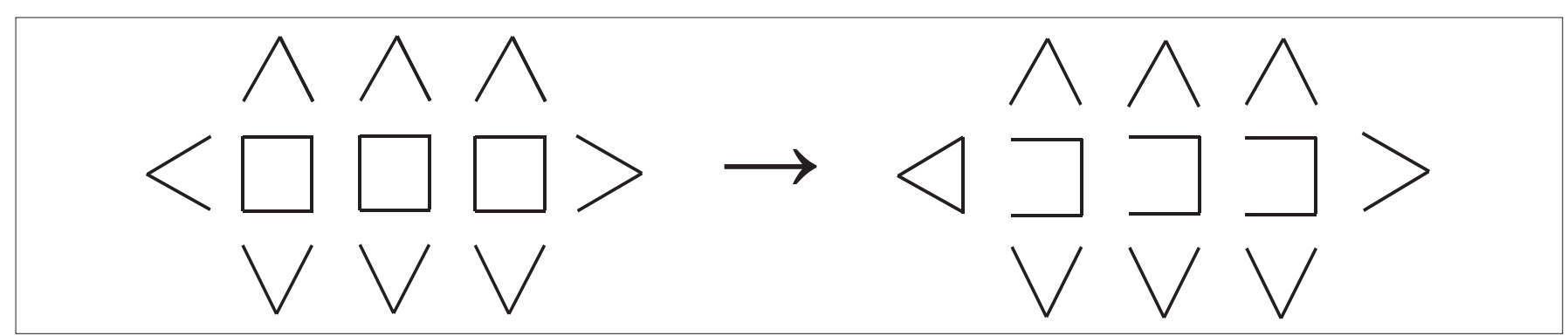

FIGURE 9: Terry's change in visual apprehension to a local visualisation.

specifically refers to 'squares', these structural features are not reflected in his present visualisation. Although his initial visualisation was suggestive of overlapping squares, he has in essence reverted to a previous visualisation in which the central structure is seen not in terms of overlapping squares but rather in terms of a series of backward C-shapes (Figure 9).

A possible explanation for this reversion to an earlier visualisation is that Terry's focus on the recursive nature of the construction process supported a local generalisation, but not a global one. A global generalisation or visualisation would entail seeing the structure in a holistic manner as being composed of a series of $n$ overlapping squares. Since four matches are needed for each square, the $n$ squares would require a total of $4 n$ matches. However, this would lead to an overcount since overlapping would mean that some matches would in effect have been counted twice. To correct for this, we would need to subtract $n-1$ matches from the tally since $n$ overlapping squares would have $n-1$ overlaps. However, Terry's constant focus on a recursive, step-by-step process of construction is incompatible with this global view. To proceed from one term to the next would require the addition of a square and the removal of the overlapping match each time. The addition of a whole square each time thus becomes a redundant process if the overlapping match is immediately removed, since the process could be accomplished in a far simpler manner by just adding on three matches in the form of a backward C-shape each time, thereby avoiding the unnecessary removal of the overlapping match. It is this focus on a stepwise process of construction that is likely to have contributed to the initial visualisation of overlapping squares being transformed into a visualisation of backward C-shapes.

At this point I asked Terry what had happened to his initial idea of focusing on the squares:

I don't know, I had something ... I was busy looking at it and something hit me and then I lost it. I noticed something to do with $n$ minus, open brackets $n$ minus 1 , and then that in brackets [i.e. $(n-(n-1))]$, that had something to do with it, but I cannot for the life of me remember what it was. (Samson, 2011b, p. 137)

Terry's reference to his noticing something to do with $(n-(n-1))$ does not initially seem to make any sense as the expression simplifies to +1 . However, it retains an interesting remnant of his initial visualisation in which there are $n$

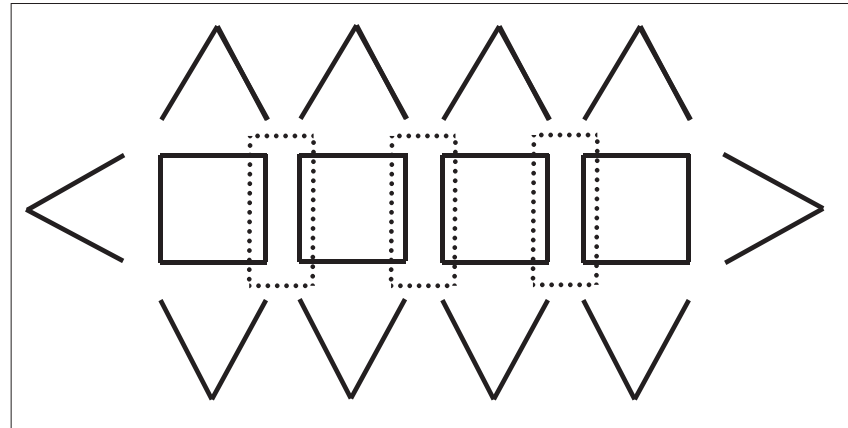

FIGURE 10: Terry's final global visualisation of overlapping squares.

overlapping squares with $n-1$ overlaps. At my suggestion he continued to pursue his initial idea. After staring at the diagrams for about half a minute he commented:

I think I might have found it ... So what I'm trying to do is now, is almost separate it so you've got, you just put all the squares together (...) and then take out this extra match right at the end [pointing in turn to each of the three overlaps between the four squares in Term 4]. (Samson, 2011b, p. 137)

This marks the crucial moment when Terry changes from a local to a global visualisation (Figure 10) and is thus able to make sense of, and articulate, his initial fleeting visualisation. After trying to incorporate $(n-(n-1))$ into his general expression, he eventually abandoned it and came up with the final formula $2+4 n-(n-1)+4 n+2$ :

That works, then you've got your 2 that starts it off [indicating the leftmost < shape], your 2 that finishes it off [indicating the rightmost $>$ shape], you've got your four for each square, then the $-(n-1)$ (...) for each square there's an extra line except for the first (...) then $+4 n$ for each triangle above and below it. (Samson, 2011b, p. 137)

\section{Concluding comments}

The vignette serves to illustrate the subtle underlying tensions that can exist as pupils engage with pictorial pattern generalisation tasks. Within the context of figural pattern generalisation, the processes of visualisation and generalisation are deeply interwoven. Pattern generalisation rests on an ability to grasp a commonality from a few elements of a sequence, an awareness that this commonality is applicable to all the terms of the sequence, and finally being able to use it to articulate a direct expression for the general term. There are thus two important aspects of this notion of generalisation, namely, (1) a phenomenological element related to grasping the generality, and (2) a semiotic element related 
to the sign-mediated articulation of what is noticed in the phenomenological realm (Radford, 2006, p. 5).

Although competing visualisations have been shown to cause tension, the crucial aspect relates to the process of coming to realise how the visualisation is regular, and how this regularity can be expressed in an algebraically useful manner. Thus, although both local and global visualisations can be useful in their own particular way, it is likely that the process of objectifying and articulating an appropriate algebraic expression for the general term is complicated when tension exists between these two modes of visualisation. An awareness of and appreciation for these subtle tensions has the potential to provide an added depth of engagement for a sensitive practitioner.

\section{Acknowledgements}

The financial assistance of the National Research Foundation (NRF) towards this research is hereby acknowledged. Opinions expressed and conclusions arrived at, are those of the author and are not necessarily to be attributed to the NRF. This work is based on research supported by the FirstRand Foundation Mathematics Education Chairs Initiative of the FirstRand Foundation, Rand Merchant Bank and the Department of Science and Technology. Any opinion, findings, conclusions or recommendations expressed in this material are those of the author and therefore the FirstRand Foundation, Rand Merchant Bank and the Department of Science and Technology do not accept any liability with regard thereto.

\section{Competing interests}

The author declares that he has no financial or personal relationships which may have inappropriately influenced him in writing this article.

\section{References}

Davis, B. (1995). Why teach mathematics? Mathematics education and enactivis theory. For the Learning of Mathematics, 15(2), 2-9. Available from http://www. jstor.org/stable/40248172

Davis, B. (1997). Listening for differences: An evolving conception of mathematics teaching. Journal for Research in Mathematics Education, 28(3), 355-376. http:// dx.doi.org/10.2307/749785

De Jager, T. (2004). Introducing and teaching first-degree equations. Learning and Teaching Mathematics, 1, 8-11.

Duval, R. (1998). Geometry from a cognitive point of view. In C. Mammana, \& V. Villan (Eds.), Perspectives in the teaching of geometry for the 21st century (pp. 37-52). Boston, MA: Kluwer.

Duval, R. (2006). A cognitive analysis of problems of comprehension in a learning of mathematics. Educational Studies in Mathematics, 61(1/2), 103-131. http:// dx.doi.org/10.1007/s10649-006-0400-z

Fischbein, E. (1993). The theory of figural concepts. Educational Studies in Mathematics, 24(2), 139-162. http://dx.doi.org.za/10.1007/BF01273689

Helson, H. (1933). The fundamental propositions of Gestalt psychology. Psychological Review, 40, 13-32. http://dx.doi.org/10.1037/h0074375
Hershkowitz, R., Dreyfus, T., Ben-Zvi, D., Friedlander, A., Hadas, N., Resnick, T., et al. (2002). Mathematics curriculum development for computerised environments: A designer-researcher-teacher-learner activity. In L.D. English (Ed.), Handbook A international research in mathematics education (pp. 657-694). Mahwah, NJ: of international research in math

Hewitt, D. (1992). Train spotters' paradise. Mathematics Teaching, 140, 6-8.

Katz, D. (1951). Gestalt psychology: Its nature and significance. London: Methuen.

Mason, J., Graham, A., Pimm, D., \& Gowar, N. (1985). Routes to/Roots of algebra. Milton Keynes: Open University Press.

Maturana, H.R., \& Varela, F.J. (1998). The tree of knowledge: The biological roots of human understanding (rev. edn.). Boston, MA: Shambhala.

Pegg, J., \& Redden, E. (1990). From number patterns to algebra: The important link. The Australian Mathematics Teacher, 46(2), 19-22.

Radford, L. (2000). Signs and meanings in students' emergent algebraic thinking: A semiotic analysis. Educational Studies in Mathematics, 42(3), 237-268. http:// dx.doi.org/10.1023/A:1017530828058

Radford, L. (2003). Gestures, speech, and the sprouting of signs: A semiotic-cultural approach to students' types of generalization. Mathematical Thinking and approach to students types of generalization. Mathematical Thinking
Learning, 5(1), 37-70. http://dx.doi.org/10.1207/S15327833MTL0501_02

Radford, L. (2005a). The semiotics of the schema: Kant, Piaget, and the calculator. In M.H.G. Hoffmann, J. Lenhard, \& F. Seeger (Eds.), Activity and sign - grounding mathematics education (pp. 137-152). New York, NY: Springer.

Radford, L. (2005b). Why do gestures matter? Gestures as semiotic means of objectification. In H.L. Chick, \& J.L. Vincent (Eds.), Proceedings of the 29th Conference of the International Group for the Psychology of Mathematics Education, Vol. 1 (pp. 143-145). Melbourne: PME.

Radford, L. (2006). Algebraic thinking and the generalization of patterns: A semiotic perspective. In S. Alatorre, J.L. Cortina, M. Sáiz, \& A. Méndez (Eds.), Proceedings of the 28th Annual Meeting of the North American Chapter of the International Group for the Psychology of Mathematics Education, Vol. 1 (pp. 2-21). Mérida, Mexico: Universidad Pedagógica Nacional.

Radford, L. (2008). Iconicity and contraction: a semiotic investigation of forms of algebraic generalizations of patterns in different contexts. ZDM: The International Journal on Mathematics Education, 40(1), 83-96. http://dx.doi.org/10.1007/ s11858-007-0061-0

Reid, D.A. (2002). Conjectures and refutations in Grade 5 mathematics. Journal for Research in Mathematics Education, 33(1), 5-29. http://dx.doi. Journal for Research
org/10.2307/749867

Sabena, C., Radford, L., \& Bardini, C. (2005). Synchronizing gestures, words and actions in pattern generalizations. In H.L. Chick, \& J.L. Vincent (Eds.), Proceedings of the 29th Conference of the International Group for the Psychology of Mathematics Education, Vol. 4 (pp. 129-136). Melbourne: PME.

Samson, D.A. (2007). An analysis of the influence of question design on pupils approaches to number pattern generalisation tasks. Unpublished master's thesis. Rhodes University, Grahamstown, South Africa. Available from http://eprints. ru.ac.za/1121/

Samson, D. (2011a). Capitalising on inherent ambiguities in symbolic expressions of generality. The Australian Mathematics Teacher, 67(1), 28-32.

Samson, D. (2011b). The heuristic significance of enacted visualisation. Unpublished doctoral dissertation. Rhodes University, Grahamstown, South Africa. Available from http://eprints.ru.ac.za/2881/

Samson, D., \& Schäfer, M. (2011). Enactivism, figural apprehension and knowledge objectification: An exploration of figural pattern generalisation. For the Learning of Mathematics, 31(1), 37-43.

Simmt, E. (2000). Mathematics knowing in action: A fully embodied interpretation In E. Simmt, B. Davis, \& J.G. McLoughlin (Eds.), Proceedings of the 2000 Annual Meeting of the Canadian Mathematics Education Study Group (pp. 153-159). Montreal: Université du Québec à Montréal.

Thornton, S. (2001). A picture is worth a thousand words. In A. Rogerson (Ed.), New Ideas in Mathematics Education: Proceedings of the International Conference of the Mathematics Education into the 21st Century Project (pp. 251-256), Palm Cove, Queensland, Australia.

Trigueros, M., \& Lozano, M.D. (2007). Developing resources for teaching and learning mathematics with digital technologies: An enactivist approach. For the
Learning of Mathematics, 27(2), 45-51. Available from http://www.jstor.org/ stable/40248571

Varela, F.J., Thompson, E., \& Rosch, E. (1991). The embodied mind: Cognitive science and human experience. Cambridge, MA: MIT Press.

Walkowiak, T.A. (2010). An examination of algebraic reasoning: Elementary and middle school students' analyses of pictorial growth patterns. In P. Brosnan, D. B. Erchick, \& L. Flevares (Eds.), Proceedings of the 32nd Annual Meeting of the North American Chapter of the International Group for the Psychology of Mathematics Education, Vol. VI (pp. 194-201). Columbus, OH: The Ohio State University.

Wertheimer, M. (1938). Laws of organization in perceptual forms. Summary of Wertheimer, M. (1923) "Untersuchungen zur lehre von der gestalt," II, Psychol. Forsch., 4: 301-350. In W.D. Ellis (Ed.), A source book of gestalt psychology (pp. 71-88). London: Kegan Paul.

Zusne, L. (1970). Visual perception of form. New York, NY: Academic Press. 